\title{
No apparent association between HLA and multiple sclerosis in southern Chinese
}

\author{
B R HAWKINS, ${ }^{*}$ Y L YU, $\dagger$ E WOO, $†$ C Y HUANG $\dagger$ \\ From the Departments of Pathology* and Medicine† University of Hong Kong, Hong Kong
}

SUMMARY HLA-A, -B and -DR antigens have been studied in 34 Chinese patients with multiple sclerosis and 100 normal healthy controls. Unlike patients of other ethnic groups in whom multiple sclerosis is associated with HLA-DR2, there was no obvious association with any HLA antigen in the Chinese patients, although the overall distribution of antigens did not appear typical of the southern Chinese population from which the patients were drawn.

The association of multiple sclerosis with HLA-DR2 and to a lesser extent with A3 and B7 has been established clearly in a number of studies in Caucasians. ${ }^{1}$ Other ethnic groups show variable HLA-A and -B associations with the disease but, with the exception of Japanese and Israelis, the association with DR2 remains a frequent finding. Multiple sclerosis is a rare disease in Chinese and only one study of HLA associations in Chinese patients has been published to date. $^{2}$ This paper examines the distribution of HLAA, -B and -DR antigens in a group of 34 southern Chinese patients in Hong Kong.

\section{Subjects and methods}

Patients 34 patients with multiple sclerosis, 21 females and 13 males, representing the majority of cases in Hong Kong were identified through a territory-wide investigation of the disease (in preparation). The diagnosis was based on a detailed neurological examination supported by relevant laboratory investigations. Patients were classified using the criteria proposed by Poser et al. ${ }^{3}$ Twenty three patients satisfied the criteria for classification as clinically definite, five as laboratory supported definite and six as clinically probable. All patients originated from Hong Kong or Guangdong Province in southern China.

Controls One-hundred normal healthy southern Chinese controls were obtained from hospital staff, university staff and students. Volunteers were not included in the control group if it was known that one or more or their parents or

Address for reprint requests: Dr B R Hawkins, Department of Pathology, University of Hong Kong, Queen Mary Hospital, Hong Kong.

Received 4 August 1987 and in revised form 20 October 1987. Accepted 26 October 1987 recent ancestors had originated outside Hong Kong or Guangdong Province.

HLA typing Patients and controls were tested for HLA$A,-B$, and -DR antigens using the standard lymphocyte microcytotoxicity test. All were tested using "Oriental" $A B C$ and DR typing trays purchased from One Lambda, Inc., California. These trays were supplemented by antisera obtained from local donors or from laboratories overseas.

Statistical analysis HLA antigen frequencies in patients and controls were compared using a $2 \times 2$ contingency analysis ( $\chi^{2}$ test) incorporating Yate's correction for each antigen.

\section{Results}

HLA antigen frequencies in patients and controls are shown in the table. Generally, the agreement between patients and controls was close, both when the patients were considered in total and when the patients with clinically definite disease were considered separately. For none of the antigen comparisons was the chi-square value greater than 3.84 which would suggest statistical significance at the $5 \%$ level. Interestingly, however, among the antigens possessed by the 34 patients were some which are not seen typically in southern Chinese. One of the patients provided the first example of HLA-Bw52 and another the first example of HLA-A32 seen during the testing of over 2,000 southern Chinese in Hong Kong. Four of the patients $(11.8 \%)$ possessed antigens having characteristics of A30 and A31 whereas these antigens normally occur in only approximately $3 \%$ of southern Chinese. In each case the antigen assignment was confirmed using appropriate international workshop sera. HLA-Bw46, which is a typically southern Chinese antigen, occurred in only $11.8 \%$ of the 
Table HLA antigen frequencies in Chinese patients with multiple sclerosis and normal controls

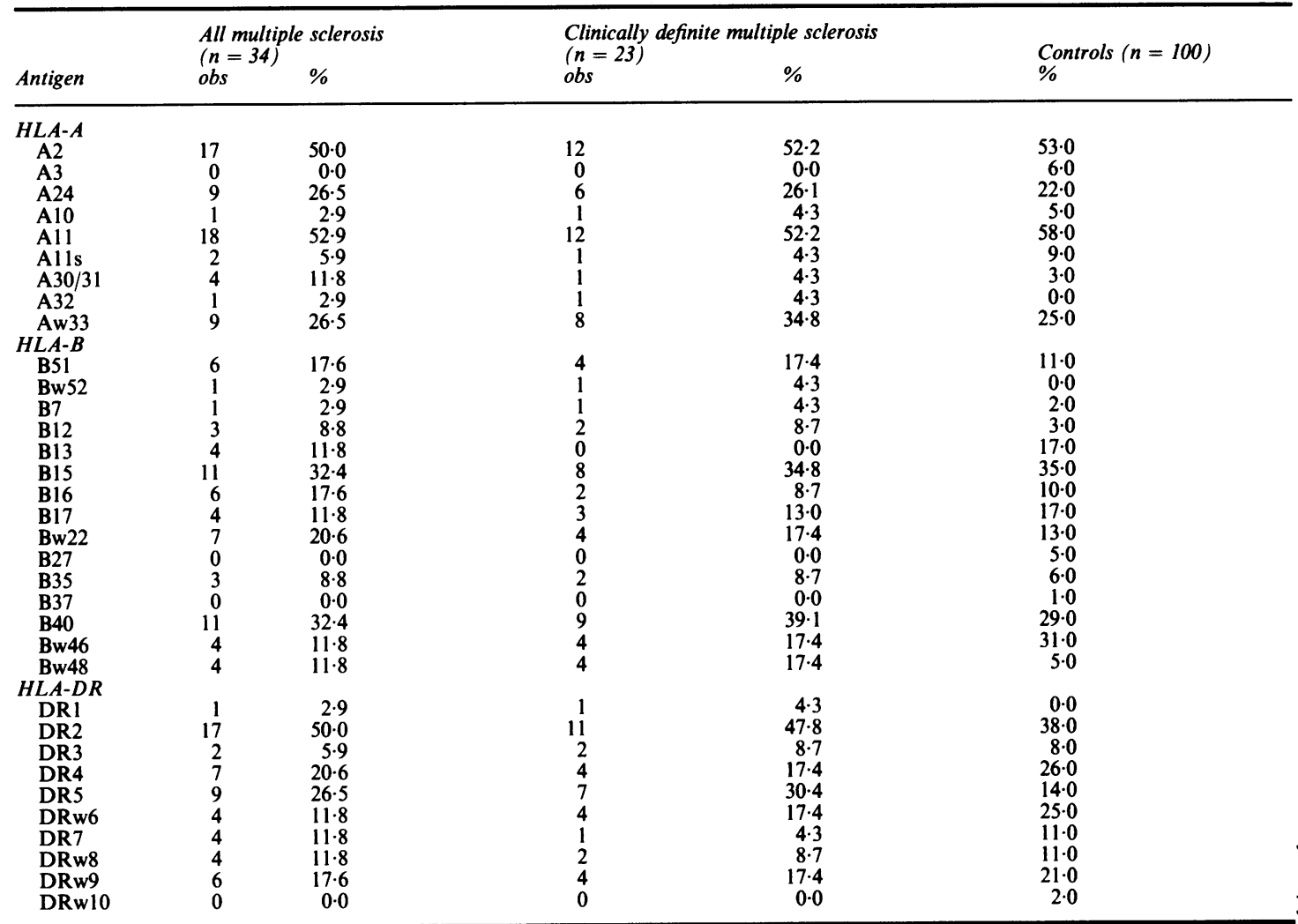

patients compared with $31 \%$ of normal controls. HLA-DR2, which is associated with multiple sclerosis in other ethnic groups, occurred in $50 \%$ of the patients compared with $38 \%$ of controls but the difference was not statistically significant.

\section{Discussion}

Multiple sclerosis is a rare disease in Orientals, with a prevalence of about $0 \cdot 8 / 100,000$ in Hong Kong Chinese (in preparation). This study of 34 Chinese patients with multiple sclerosis, representing most of the known patients from Hong Kong's population of 5.7 million, has shown no apparent association of the disease with any particular HLA antigen. In other ethnic groups the disease has been shown consistently to be associated with HLA-DR2, with the notable exception of Israelis ${ }^{4}$ and Japanese. ${ }^{5}$ A recent study of Chinese patients in Sichuan Province in central China also showed no association with HLA-DR antigens but reported associations with B16 and Bw22. ${ }^{2}$ These antigens were not associated with multiple sclerosis in the present study of southern Chinese.

Of particular interest in the present study was the finding that, although there were no statistically significant differences between patients and controls in terms of individual antigens, the overall distribution of antigens was not characteristic of the southern Chinese population. A32 and Bw52 were detected for the first time in southern Chinese, A30 and A31 occurred with four times their normal frequency, and Bw46 which is a typically southern Chinese antigen occurred with less than half its usual frequency. None of these findings were statistically significant individually, but taken as a whole could suggest the possible presence of HLA genes within the multiple sclerosis patients that have been introduced from outside the normal southern Chinese gene pool.

The strong association of HLA-DR2 with multiple sclerosis in Caucasians and the absence of an obvious HLA association in Chinese presents an interesting anomaly. It may be relevant to note that HLA-DR2 in normal Caucasians contains at least two sero- 
logical subtypes with characteristic DNA patterns using $\mathrm{DQ} \alpha$ and $\mathrm{DQ} \beta$ probes. ${ }^{67}$ At the DNA level in the Chinese, however, many DR2 cells from apparently healthy subjects do not show typical patterns with these probes. ${ }^{7}$ Thus, the possibility cannot be overlooked that although there is no general increase in the frequency of serologically-defined DR2 in Chinese patients with multiple sclerosis, all or some of the DR2 genes present could have a specific DNA pattern which is common to multiple sclerosis. Studies of these patients at the DNA level would seem essential to exclude a true HLA association with multiple sclerosis in Chinese.

We thank the following colleagues for referring patients under their care: Drs C W Keung, K F Ko, S $\mathrm{C}$ Kwong and $\mathrm{P} \mathrm{Li}$ of the Department of Medicine, Queen Elizabeth Hospital; Dr B Tse of the Government Medical Unit, Queen Mary Hospital; Dr D Chin of United Christian Hospital; and Drs E Cheung, F S Lui and $\mathrm{S} \mathrm{H} \mathrm{Ng}$ in private medical practice.

\section{References}

1 Tiwari JL, Terasaki PI. HLA and Disease Associations. New York: Springer-Verlag, 1985:152-67.
2 Pei J, Xu WZ, Sun SX, et al. HLA and Chinese multiple sclerosis. In: Aizawa M, Natori T, Wakisaka A, Konoeda Y, eds. HLA in Asia-Oceania 1986. Proceedings of the third Asia-Oceania Histocompatibility Workshop and Conference. Sapporo: Hokkaido University, 1986:726-9.

3 Poser CM, Paty DW, Scheinberg L, et al. New diagnostic criteria for multiple sclerosis: guidelines for research protocols. Ann Neurol 1983;13:227-31.

4 Brautbar C, Amar A, Cohen N, et al. HLA-D typing in multiple sclerosis: Israelis tested with European homozygous typing cells. Tissue Antigens 1982;19:189-97.

5 Tiwari JL, Morton NE, Lalouel JM, et al. Multiple sclerosis. In: Terasaki PI, ed. Histocompatibility Testing 1980. Los Angeles: UCLA Tissue Typing Laboratory, 1980:687-92.

6 Nishimura Y, Tsukamoto K, Sone T, et al. Molecular and functional analysis of Class II molecules characteristic to HLA-Dw2 and Dw12. In: Albert ED, Baur MP, Mayr WR, eds. Histocompatibility Testing 1984. Berlin: Springer-Verlag, 1984:504-8.

7 Kohonen-Corish MRJ, White BS, Hawkins BR, Serjeantson SW. HLA-DR and -DQ RFLPs in Hong Kong Chinese. In: Aizawa M, Natori T, Wakisaka A, Konoeda Y, eds. HLA in Asia-Oceania 1986. Proceedings of the third Asia-Oceania Histocompatibility Workshop and Conference. Sapporo: Hokkaido University, 1986:454-7. 